\title{
Comparison and integration of ice-pack temperatures derived from AVHRR and passive microwave imagery
}

\author{
J. MASLANIK AND J. Key \\ Division of Cryospheric and Polar Processes, Cooperative Institute for Research in Environmental Sciences, University of Colorado, \\ Boulder, CO 80309-0449, U.S.A.
}

\begin{abstract}
Co-located sets of AVHRR and SSM/I passive microwave imagery are used to estimate ice surface temperatures and to infer cloud cover in the Arctic. Physical temperatures are determined from the AVHRR data by modeling atmospheric and surface conditions. The resulting field-of-view temperatures are converted to ice surface skin temperatures by adjusting for ice concentration calculated using the SSM/I data. By selecting AVHRR-derived temperatures for clear sky conditions, "effective" emissivities of first-year and multi-year ice are calculated. Given these emissivities, microwave brightness temperatures, and proportions of first-year and multi-year ice as estimated using the NASA Team Algorithm, physical temperatures of the sea ice/snow surface are calculated that are, in theory, relatively independent of cloud conditions. The resulting ice temperatures are used to delineate a portion of the cloud cover in the AVHRR data. The advantages of this approach are that only a fairly small amount of AVHRR data are needed to calibrate the SSM/I imagery that can then be used to calculate a timeseries of temperatures on a large scale.
\end{abstract}

\section{INTRODUCTION}

Ice surface temperature controls the rate of sea-ice growth, and thus is a critical parameter for sea-ice modeling and climate studies. Little effort has been directed to the retrieval of the sea ice surface temperature in the Arctic, an area where the first effects of a changing climate are expected to be seen. The reason is not one of methodology, but rather our limited knowledge of atmospheric temperature, humidity, and aerosol profiles, the microphysical properties of polar clouds and ice crystal fogs, and the spectral characteristics of the wide variety of surface types found there. Such applications require frequent sampling over large areas. NOAA Advanced Very High Resolution Radiometer (AVHRR) thermal imagery can provide ice-pack surface skin temperatures under clear-sky conditions in a manner similar to that used operationally to estimate seasurface temperatures. When clouds are present, the AVHRR-derived temperatures represent a mixture of surface and cloud-top temperatures, depending on the cloud fraction and cloud optical depth. Brightness temperatures recorded by passive microwave sensors are a function of physical temperature at frequency-dependent depths in the snow/ice column and, in general, are much less affected by atmospheric water. Passive microwave data also supply information on ice concentration and a first-order estimate of the proportion of firstyear and multi-year ice.

Snow/ice temperatures as estimated from both AVHRR and passive microwave data are functions primarily of physical temperature, emissivity, ice concentration, and ice thickness. Penetration depth in the snow/ice column increases as microwave frequency decreases. Thus, the microwave temperatures represent the physical temperature and emissivity at different depths in the ice pack (including snow on the ice surface), whereas the AVHRR-derived values represent surface or very-near-surface temperatures. The key variables in the temperature calculations are the emissivities of different surface types at the microwave frequencies, the mix of surface types in the sensors' fieldsof-view, and atmospheric effects at the AVHRR frequencies. By combining passive microwave data with AVHRR imagery, we increase the number of variables available to address the unknowns in the surface temperature problem.

Our objectives are to use physical surface temperatures derived from AVHRR imagery $\left(T_{\mathrm{s} \text { (AVHRR) }}\right)$ combined with Defense Meteorological Satellite Program (DMSP) Special Sensor Microwave/Imager (SSM/I) passive microwave data to convert AVHRR-derived surface temperature $T_{\mathrm{s} \text { (AVHRR) }}$ (which includes a mixture of temperatures of water and ice within the field-of-view) to ice surface temperature $T_{\mathrm{ice} \text { (AVHRR); }}$ and to use the resulting $T_{\text {ice(AVHRR) }}$ to convert the passive microwave brightness temperatures $T_{\mathrm{B}}$ to physical, passive microwave-derived surface temperature $T_{\mathrm{ice}}$ (PM) (or, at specific frequencies, $\left.T_{\text {ice(19V) }}, T_{\text {ice(37V) }}, T_{\text {ice( } 85 \mathrm{H})}\right)$. In addition, since $T_{\mathrm{B} \text { (AVHRR) may actually represent both surface and }}$ atmospheric temperatures depending on cloud cover, while the SSM/I data at 19 and $37 \mathrm{GHz}$ are considerably 
less affected by atmospheric conditions, we investigate whether the combination of $T_{\text {ice(AVHRR) }}$ and $T_{\text {ice(PM) }}$ can be used as a crude discriminator of cloud cover.

\section{DATA}

AVHRR data were extracted from an image set prepared by the Naval Research Laboratory (Fetterer and Hawkins, 1991). These data consist of AVHRR Local Area Coverage imagery calibrated and mapped to a polar stereographic grid of nominal $1 \mathrm{~km}$ cell size co-registered to the DMSP SSM/I brightness temperature grid format used to archive SSM/I data (NSIDC, 1990). The images are visually screened to minimize cloudy images in the archive, but no cloud masking is performed. Images for 1 March, 17 March, 23 March, 1 December and 2 December 1989 covering portions of the Beaufort Sea were extracted and converted to $T_{\mathrm{s} \text { (AVHRR) }}$ using the procedure described below. Each AVHRR image was resampled to a grid cell size of $25 \mathrm{~km}$ to match the SSM/I grid.

Concurrent SSM/I $19 \mathrm{GHz}$ vertically polarized (19V), $37 \mathrm{GHz}$ vertically polarized $(37 \mathrm{~V})$, and $85 \mathrm{GHz}$ horizontally polarized $(85 \mathrm{H})$ brightness temperatures were extracted from the daily gridded SSM/I images archived on CD-ROM (NSIDC, 1990). Total ice concentration and multiyear ice percentages were calculated using a version of the NASA Team Algorithm (Gloersen and Cavalieri, 1986) and tie points supplied by NSIDC with the CD-ROMs. The $85 \mathrm{H}$ data (originally $12.5 \mathrm{~km} \times$ $12.5 \mathrm{~km})$ and the ice concentration output $(50 \mathrm{~km} \times$ $50 \mathrm{~km}$ ) were resampled to match the $25 \mathrm{~km}$ cell size of the $19 \mathrm{~V}$ and $37 \mathrm{~V}$ grids. These gridded data consist of averaged samples for all orbits during a $24 \mathrm{~h}$ period, whereas the AVHRR data used are for individual orbits. Thus, some error in combining the SSM/I and AVHRR data is introduced due to the time-averaging involved.

\section{METHODOLOGY}

\section{Physical temperature retrieval from AVHRR}

The general approach to estimating surface temperature is to relate satellite observations to surface-temperature observations with a regression model. Lacking sufficient observations however, satellite radiances or brightness temperatures can be modeled by application of the radiative-transfer equation. This "forward model" approach is commonly used for retrieval of sea surface temperature. A means to correct for the atmospheric attenuation of satellite-measured clear sky brightness temperatures in the split-window thermal channels of the AVHRR sensors on-board three of the NOAA series satellites has been developed and is detailed in Key and Haefliger (1992). These corrections are specified for three different "seasons" (summer, winter, and transition between winter and summer) and as a function of satellite viewing angle, and are expected to be applicable to the perennial ice pack in the central Arctic Basin. In this analysis it is assumed that a valid cloud-clearing method exists and that only clear sky radiances are being examined. The cloud-clearing problem in polar satellite data is not trivial, however. For a review of polar cloud detection algorithms, see Key and Barry (1989) and Sakellariou and others (1992).

For the retrieval of the snow/ice surface temperature a multi-channel algorithm that uses empirical relationships to correct for water vapor absorption is employed:

$$
T_{\mathrm{s}(\mathrm{AVHRR})}=a+b T_{4}+c T_{5}+d\left[\left(T_{4}-T_{5}\right) \sec \theta\right]
$$

where $T_{4}$ and $T_{5}$ are the satellite-measured brightness temperature $(\mathrm{K})$ in the AVHRR thermal channels and $\theta$ is the sensor scan angle. The coefficients are determined through a least-squares regression procedure, where surface temperatures are regressed against modeled brightness temperatures. To model radiances in the AVHRR thermal channels, daily temperature and humidity profiles collected by rawinsonde from a Soviet ice island (NP-26), located at approximately $85^{\circ} \mathrm{N}$, $170^{\circ} \mathrm{W}$ during $1983-87$ are used to describe atmospheric conditions in each season for input to the LOWTRAN 7 radiative transfer model (Kneizys and others, 1988). Radiances are modeled for sensor scan angles from $0^{\circ}$ to $60^{\circ}$ in $10^{\circ}$ increments. The appropriate sensor response function is applied to the calculated radiances, and radiances are then converted to brightness temperatures. Atmospheric chemical composition, background tropospheric and stratospheric aerosols for the subarctic winter and summer models are used, since no such information is available from the ice islands. The optical properties of Arctic haze have not been extensively measured; model calculations (Blanchet and List, 1983) show that the volume extinction coefficient of Arctic haze is generally of the same order of magnitude as that of the tropospheric aerosols. Therefore, the use of tropospheric background aerosols is appropriate.

Concerning surface characterization, directional surface emissivities for snow are modeled as in Dozier and Warren (1982). These emissivities are then integrated with the sensor response function for each channel. The skin temperature for each temperature profile is assigned a series of values during the month to which the profile belongs. An energy balance model (Maykut, 1982) is used to determine these surface temperatures, based on the observed range of shelter temperatures and wind speeds (the mean \pm 1 standard deviation) in the ice island data for each month. Overall, the accuracy of the estimated surface temperatures is approximately $0.1 \mathrm{~K}$ (Key and Haefliger, 1992). This value will be slightly larger in practice, since the sensor noise and model bias have not been taken into account.

As noted earlier, the AVHRR temperatures represent the integrated temperatures of all the surfaces within the field-of-view. Over pack ice, the resulting surface temperature can thus be a mixture of the surface temperatures of thick ice, thin ice and open water. Since we are primarily interested in the surface temperatures of the ice itself, we can combine $T_{\mathrm{s}(\mathrm{AVHRR})}$ and the SSM/Iderived ice concentrations to determine $T_{\text {ice(AVHRR), }}$, where:

$$
T_{\text {ice(AVHRR) }}=\left[T_{\mathrm{s}(\mathrm{AVHRR})}-T_{\text {water }}\left(1-C_{\text {tot }}\right)\right] / C_{\text {tot }} .
$$

$T_{\text {water }}$, the physical temperature of open water, is taken to be a salinity-adjusted $271.2 \mathrm{~K}$. $C_{\text {tot }}$ is the total ice 
concentration estimated from the SSM/I data. This approach ignores the effects of thin ice, but should be valid as a first approximation. At the thermal wavelengths considered here, we assume emissivities to be unity for both ice and water. For typical mid-winter ice concentrations and temperatures, a $5 \%$ error in $C_{\text {tot }}$ yields an error in $T_{\mathrm{ice}(\mathrm{AVHRR})}$ of about $1 \mathrm{~K}$.

\section{Passive microwave-derived temperatures and emissivities}

Since $T_{\mathrm{ice}(\mathrm{AVHRR})}$ is a skin or very-near-surface temperature, emissivities affecting $T_{\mathrm{ice}(\mathrm{AVHRR})}$ are not the same as the emissivities affecting the passive microwave $T_{\mathrm{B}}$, due to the penetration depth at the passive microwave frequencies. We can consider our calculated emissivities as "effective" emissivities, $\varepsilon^{\prime}$, that yield the appropriate skin temperature relative to the passive microwave $T_{\mathrm{B}}$.

To calculate the physical temperature at the radiating layer from passive microwave data, we expand on the approach described by Cavalieri and others (1984):

$$
\begin{aligned}
T_{\mathrm{PM}}(f)= & {\left[T_{\mathrm{B}}(f)-\left(T_{\text {water }} \varepsilon_{\text {water }}(f)\right)\left(1 / C_{\mathrm{fy}}-C_{\mathrm{my}}\right)\right] / } \\
& \left(\varepsilon_{\mathrm{fy}} C_{\mathrm{fy}}\right)+\left(\varepsilon_{\mathrm{my}} C_{\mathrm{my}}\right)
\end{aligned}
$$

where $f$ represents a particular frequency and polarization, $\varepsilon$ is the radiating-layer emissivity, $C$ is ice concentration, $T_{\mathrm{B}}$ is brightness temperature, fy represents first-year ice, and my represents multi-year ice. $T_{\mathrm{PM}}$ is the temperature of the radiating layer whereas

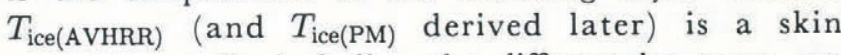
temperature. By including the different ice types, we can estimate $T_{\mathrm{PM}}$ at finer spatial resolution by using higher frequencies (compared to $T_{\mathrm{PM}}$ estimated using lower frequencies, since spatial resolution increases as frequency increases) where the variation in emissivity between first-year and multi-year ice is significant. The limitations of this simple method are that the emissivities and concentrations of the different ice types and open water must be provided. Since the NASA Team Algorithm operates essentially independently of physical temperature (Cavalieri and others, 1984) the derived concentrations are valid for our purpose. The largest sources of error lie in the emissivities and in the algorithmderived multi-year ice concentration. A per cent error in emissivities translates into an equivalent per cent error in $T_{\text {ice(PM) }}$. We therefore need to consider how to estimate the emissivities and how to minimize the error due to uncertainties in the $C_{\mathrm{my}}$.

Since at microwave frequencies, $\varepsilon=T_{\mathrm{B}} / T_{\mathrm{PM}}$, we can estimate an "effective" emissivity, $\varepsilon^{\prime}$, using $T_{\mathrm{B}}$ and $T_{\text {ice(AVHRR) }}$, bearing in mind that $T_{\text {ice(AVHRR) }}$ represents clear-sky surface temperatures. The relationship between the passive microwave-derived skin temperature, $T_{\text {ice(PM) }}$, the effective emissivity and the brightness temperature $T_{\mathrm{B}}$ is now $T_{\mathrm{ice}(\mathrm{PM})}=T_{\mathrm{B}} / \varepsilon^{\prime}$. However, $\varepsilon^{\prime}$ differs for first-year and multi-year ice, with the difference being greatest at higher frequencies. If we choose only areas that have ice concentrations close to $100 \%$ and accept the NASA Team Algorithm's output, we can reduce the equation to two unknowns,

$$
\varepsilon_{\mathrm{fy}}^{\prime} C_{\mathrm{fy}}+\varepsilon_{\mathrm{my}}^{\prime} C_{\mathrm{my}}=T_{\mathrm{B}} / T_{\mathrm{ice}(\mathrm{AVHRR})}
$$

Table 1. Effective emissivities, $\varepsilon^{\prime}$, estimated using $T_{\text {ice(AVHRR), }}, S S M / I$-derived concentrations, and Equation (4)

$100 \%$ first-year ice $\quad 100 \%$ multi-year ice

$\begin{array}{lll}19 \mathrm{~V} & 1.016 & 1.000 \\ 37 \mathrm{~V} & 0.995 & 0.849 \\ 85 \mathrm{H} & 0.883 & 0.680\end{array}$

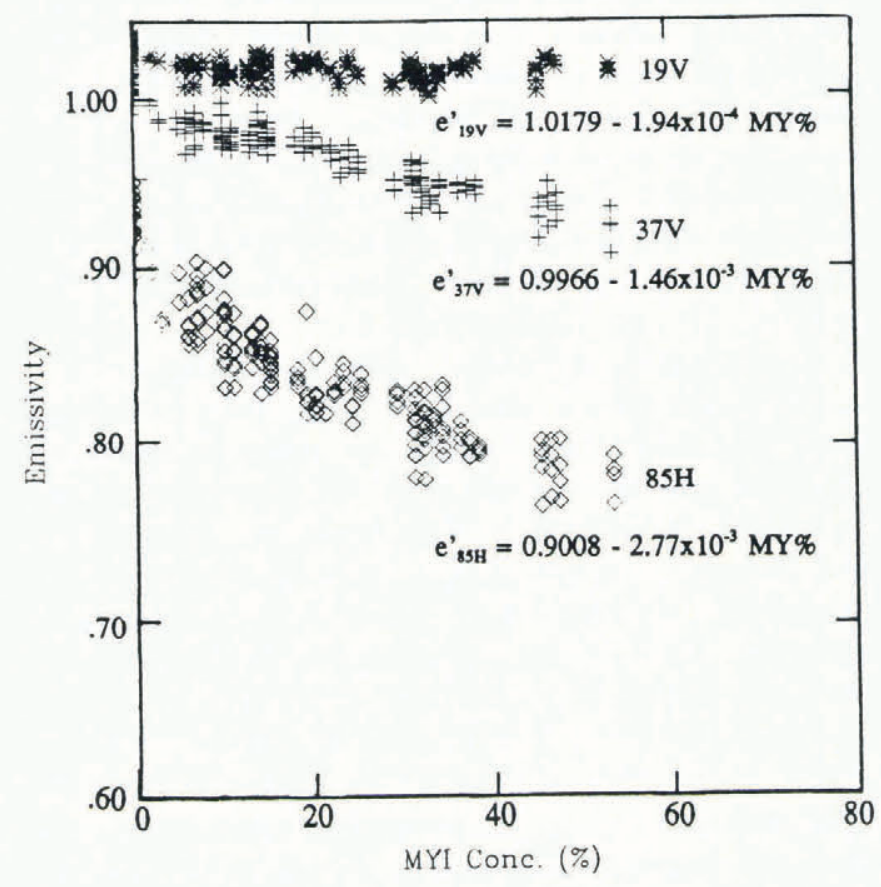

Fig. 1. "Effective" emissivity at $19 \mathrm{~V}, 37 \mathrm{~V}$ and $85 \mathrm{H}$ versus multi-year ice concentration, for total ice concentrations of 99-100\%. Emissivities are derived from AVHRR ice surface temperatures relative to the multi-year ice percentage estimated using the NASA Team Algorithm.

that can be solved as a set of simultaneous equations given multiple observations. We selected $T_{\mathrm{s} \text { (AVHRR) }}$ for a relatively clear-sky region in the 1 December AVHRR temperature image and used the corresponding ice concentration image to select only those pixels with $C_{\text {tot }}$ greater than or equal to $99 \%$. Based on these samples and solving Equation (4) yields the emissivities in Table 1. We reiterate that the estimate of multi-year ice concentration from the NASA Team Algorithm (e.g. the tie points used to represent the different ice types) defines the relationship between effective emissivity and ice type mixture. Thus, if $T_{\text {ice(AVHRR) }}$ is available, the calculation of surface temperature from the SSM/I data is independent of the actual emissivity of the ice.

The high values for $\varepsilon^{\prime}$ at $19 \mathrm{~V}$ likely reflect the greater penetration depth at this frequency, since temperatures deeper in the ice or at the snow/ice interface are likely to be higher than the skin temperatures, given the typical winter conditions of heat conduction from the ocean upward through the ice column. As expected, the 
difference in emissivity between ice types increases with frequency due to volume scattering. Since we know that one of the largest sources of error in our approach is the potential error in the estimated multi-year ice percentage, the effect of this error on the ice temperature retrievals can be minimized by using the $19 \mathrm{GHz}$ data.

Using data from a region that appears to be relatively cloud-free in the 1 December image, we illustrate the frequency relationship between emissivity and multi-year ice percentage for near- $100 \%$ ice cover more clearly in Figure 1 . In addition to showing the change in emissivity with frequency, this plot suggests a second approach to calculate $\varepsilon^{\prime}$ - simply fitting a line through each frequency's data. The resulting equations are shown on the figure. Using these relationships, we arrive at the set of $\varepsilon^{\prime}$ listed in Table 2. Both sets of $\varepsilon^{\prime}$ are similar. Subsequent calculations of $T_{\mathrm{ice}(\mathrm{PM})}$ (e.g., $T_{\mathrm{ice}(19 \mathrm{~V}) \text {, }}$ $T_{\text {ice( }(37 \mathrm{~V})}$, and $\left.T_{\mathrm{ice}(85 \mathrm{H})}\right)$ from the $\mathrm{SSM} / \mathrm{I}$ data use the emissivities in Table 1 .
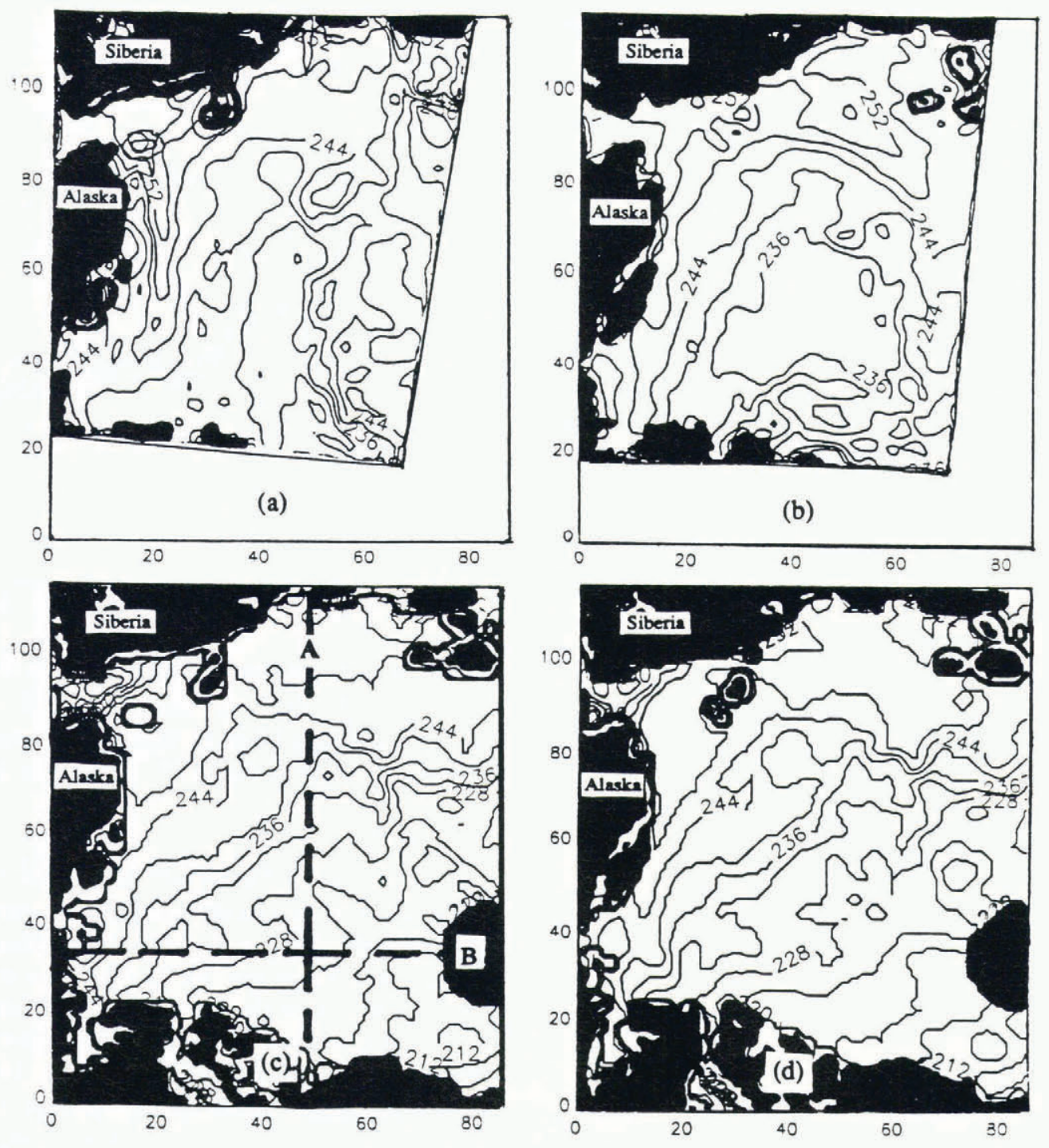

Fig. 2. Temperatures derived from AVHRR data for 1 December 1989 (a), 2 December 1989 (b). Surface temperatures derived from SSM/I 19V for 1 December 1989 (c) and 2 December 1989 (d). The area shown is a polar stereographic projection covering the western Arctic. Isotherm intervals are $K$. Land is masked out as black in the AVHRR and the SSM/I data, and the missing data zone around the pole is masked out as cross-hatching in the SSM/I data. Locations of sample transects (transects $A$ and $B$ ) are shown by the heavy dashed lines labeled " $A$ " and " $B$ " in Figure $2 c$.
Table 2. Effective emissivities for $100 \%$ first-year ice and $100 \%$ multi-year ice estimating using a linear fit of $\varepsilon^{\prime}$ vs multi-year ice percentage

$100 \%$ first-year ice $\quad 100 \%$ multi-year ice

$\begin{array}{lll}19 \mathrm{~V} & 1.018 & 0.992 \\ 37 \mathrm{~V} & 0.997 & 0.851 \\ 85 \mathrm{H} & 0.901 & 0.624\end{array}$

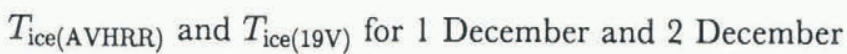
are shown in Figure 2. $T_{\text {ice(AVHRR) }}$ shows greater spatial 
variability, with some patterns suggestive of cloud cover, whereas $T_{\mathrm{ice}(19 \mathrm{~V})}$ show an overall smoother transition of temperatures. In general, the microwave-derived temperatures are lower than the AVHRR temperatures, with the difference increasing as ice temperature decreases. Since lower ice temperatures are typically associated with a greater percentage of multi-year ice, this difference may be due to an overestimate of multi-year ice emissivity. The difference may also be due to thin cloud cover or ice fog that is hard to detect by eye in the AVHRR imagery. In a few locations, just north of Point Barrow in the southern Beaufort Sea for example, $T_{\text {ice }(19 v)}$ is higher than $T_{\text {ice(AVHRR), suggesting that these are regions of high, cold }}$ cloud. Alternatively, these locations may have been closer to true "clear sky" conditions than the locations used to select clear-sky tie points, resulting in estimated effective emissivities that are too low. $T_{\text {ice }(37 \mathrm{~V})}$ are nearly identical to $T_{\text {ice(19V) }}$, while $T_{\text {ice( } 85 \mathrm{H})}$ show much more variability, due most likely to a combination of greater sensitivity to surface scattering and to atmospheric emissions. Since $85 \mathrm{H}$ has the shallowest penetration depth of the SSM/I frequencies, some of the variation may also reflect spatial variations in skin temperature, as opposed to the temperatures sensed at 19 and $37 \mathrm{GHz}$ which, due to the greater penetration depths at these frequencies, will have a dampened spatial and temporal response compared to skin temperatures.

National Meteorological Center monthly mean surface air temperatures tend to be about $240 \mathrm{~K}$ north of about $77^{\circ}$ in December and 235-240K in March (Parkinson and others, 1987) in the western Arctic. A summary of Soviet drifting station data from the Canada Basin show mean air temperatures of $242 \mathrm{~K}$ in March and $244 \mathrm{~K}$ in December while drifting buoy temperatures are typically about $5 \mathrm{~K}$ higher (Maslanik, unpublished data). Given the fact that radiative cooling of the ice surface will

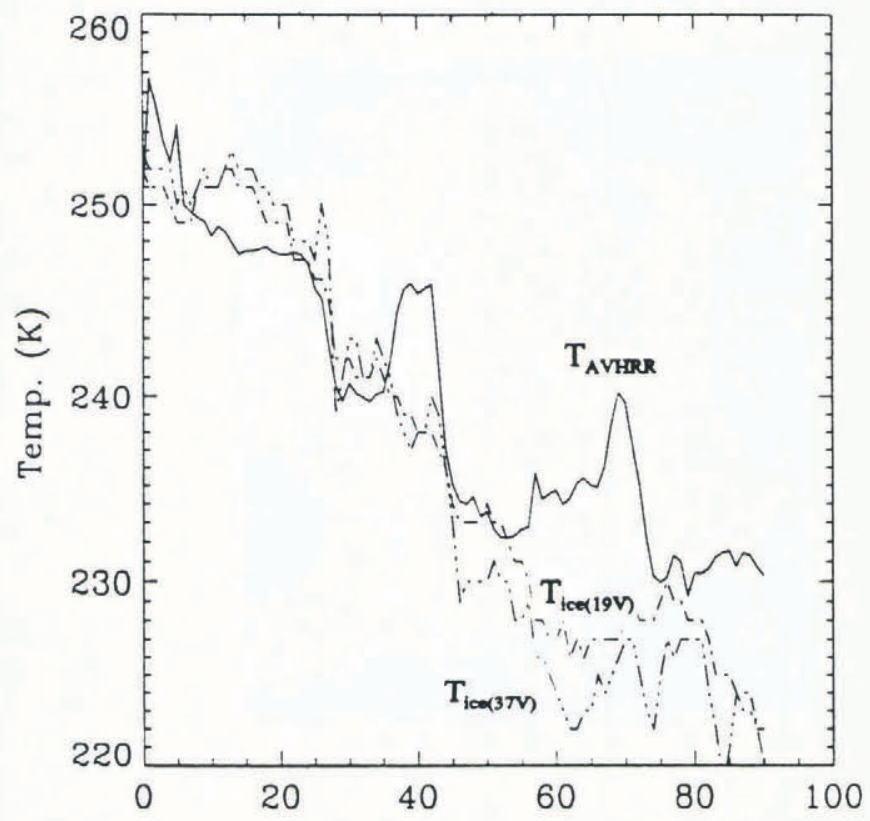

Fig. 3. Comparison of $T_{\mathrm{ice}(\mathrm{AVHRR})}\left(-\right.$ line), $T_{\mathrm{ice}(19 \mathrm{~V})}$ (-- - line), and $T_{\mathrm{ice}(37 \mathrm{~V})}(-\cdots-$ line $)$ for 1 December 1989 (a) and 2 December 1989 (b) along transect $A$ in Figure 2.
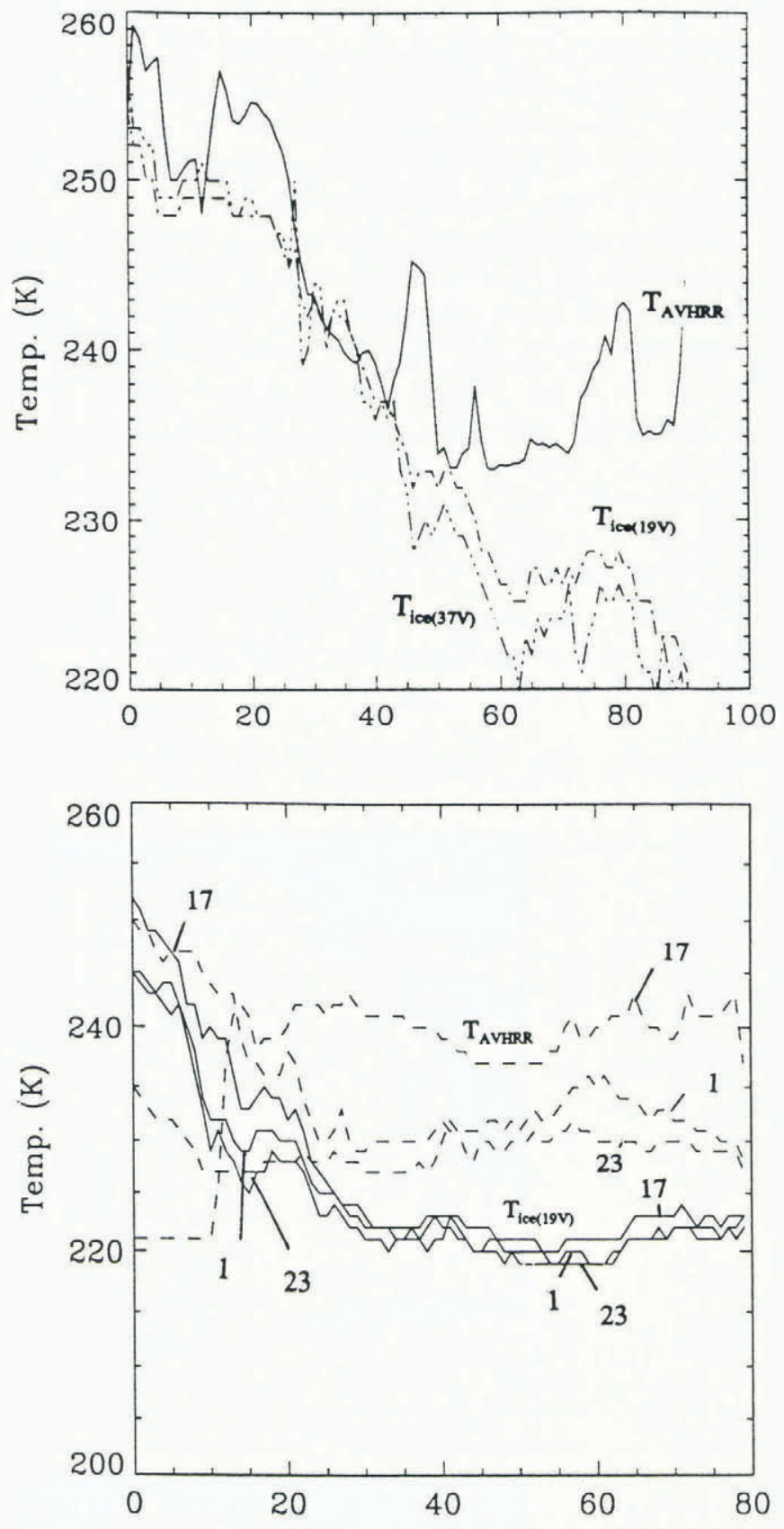

Fig. 4. Temperatures along transect $B$ in Figure 2 for 1 March, 17 March and 23 March 1989. Solid line is

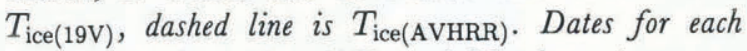
transect are shown (e.g. " 1 " = 1 March, etc.).

yield lower skin temperatures compared to air temperatures, the remotely-sensed surface temperatures are not unreasonable. A more direct comparison of $T_{\mathrm{ice}(19 \mathrm{~V}) \text {, }}$ $T_{\text {ice(37V) }}$ and $T_{\text {ice(AVHRR) }}$ is shown in the transect plots in Figures 3 and 4 for the December and March images. The microwave-derived temperatures show virtually no change along the transect from 1 December to 2 December, while considerable change is apparent in $T_{\text {ice(AVHRR), again most likely due to changes in cloud }}$ cover and atmospheric water content, and possibly to surface warming due to enhanced downwelling longwave radiation beneath the cloud cover. $T_{\text {ice(19V) }}$ and $T_{\text {ice(37V) }}$ show a realistic decrease northward and toward the Canadian Archipelago, with the same general pattern along part of the $T_{\text {ice(AVHRR) }}$ transect. The pattern of 
$T_{\text {ice(AVHRR) }}$ in the northern portions of the grids particularly the spatial pattern and the day-to-day changes such as the $14 \mathrm{~K}$ decrease at transect location 75 from 1 December to 2 December - suggest that the positive temperature bias between $T_{\text {ice(AVHRR) and }}$ $T_{\text {ice(19V) }}$ and $T_{\text {ice(37V) }}$ may be due to cloud cover rather than differences in surface temperatures as estimated using the different imagery. However, we have no independent and reliable cloud information available to verify this. Differences in $T_{\mathrm{ice}(19 \mathrm{~V})}$ and $T_{\mathrm{ice}(\mathrm{AVHRR}) \text { for } 1}$ March, 17 March and 23 March are shown in Figure 4. The change in $T_{\text {ice(19V) }}$ over time in the south suggest a possible decrease in surface air temperature over time, with little change further northward, while $T_{\text {ice(AVHRR) }}$ shows a greater variability consistent with transient cloud cover. It is also possible that the radiating temperature of the ice pack itself might be changing over time due to ridging or snowfall. To examine further the differences between the AVHRR and passive microwave-derived temperatures and the relationship to cloud cover, we compare the image of $T_{\text {ice(AVHRR) }}$ (Fig. 5a) and the image resulting from $T_{\text {ice(AVHrR) }}-T_{\text {ice(19V) }}$ (Fig. $5 \mathrm{~b}$ ) for 1 December 1989. Figure $5 \mathrm{a}$ and b show spatial patterns typical of cloud cover. In Figure $5 \mathrm{~b}, T_{\text {ice(AVHRR) is }}$ typically greater than $T_{\mathrm{ice}(19 \mathrm{~V})}$ by an average of about $2 \mathrm{~K}$ in the areas that have the appearance of cloud.

The fact that some cloud might be delineated in this way does not, however, imply that having $T_{\text {ice(PM) }}$ provides a general solution to the polar cloud detection problem. The accuracy of threshold-based cloud retrievals (e.g. all pixels that have temperatures above/below the surface temperature plus some offset) using $T_{\text {ice(PM) }}$ depends on the error in $T_{\text {ice(PM) }}$ and the temperature difference and sign of the difference between clouds and the surface. This case study presents a method for deriving $T_{\text {ice(PM) }}$, but considerably more work is needed to estimate the accuracy of the method. Regarding the cloud and surface temperature relationships, in the December data examined here, apparent cloud cover (based on manual interpretation of spatial patterns in the AVHRR temperatures) has a broad temperature range, both colder and warmer than the surface. The amount of cloud that would go undetected using a simple thresholding procedure depends obviously on the temperature differential between cloud and surface, and on the error margin of $T_{\text {ice(PM) }}$. Additionally, warm surface features such as leads and polynas may be falsely labeled as cloud. It is also important to point out that the relationship between the radiating temperature within the snowpack versus the skin temperature is complex, and few data exist to test the stability over time and space of the "clear-sky" tie points used here.

The problems noted above do not imply that passive microwave-derived surface temperatures are not useful for cloud detection algorithms. On the contrary, determining the surface temperature is the crucial step in the procedure. However, it is also clear that in the polar regions, having the surface temperature alone is generally not enough to map cloud cover, and that temporal and possibly textural characteristics must also be examined (see, for example, Key and Barry, 1989 and references therein).

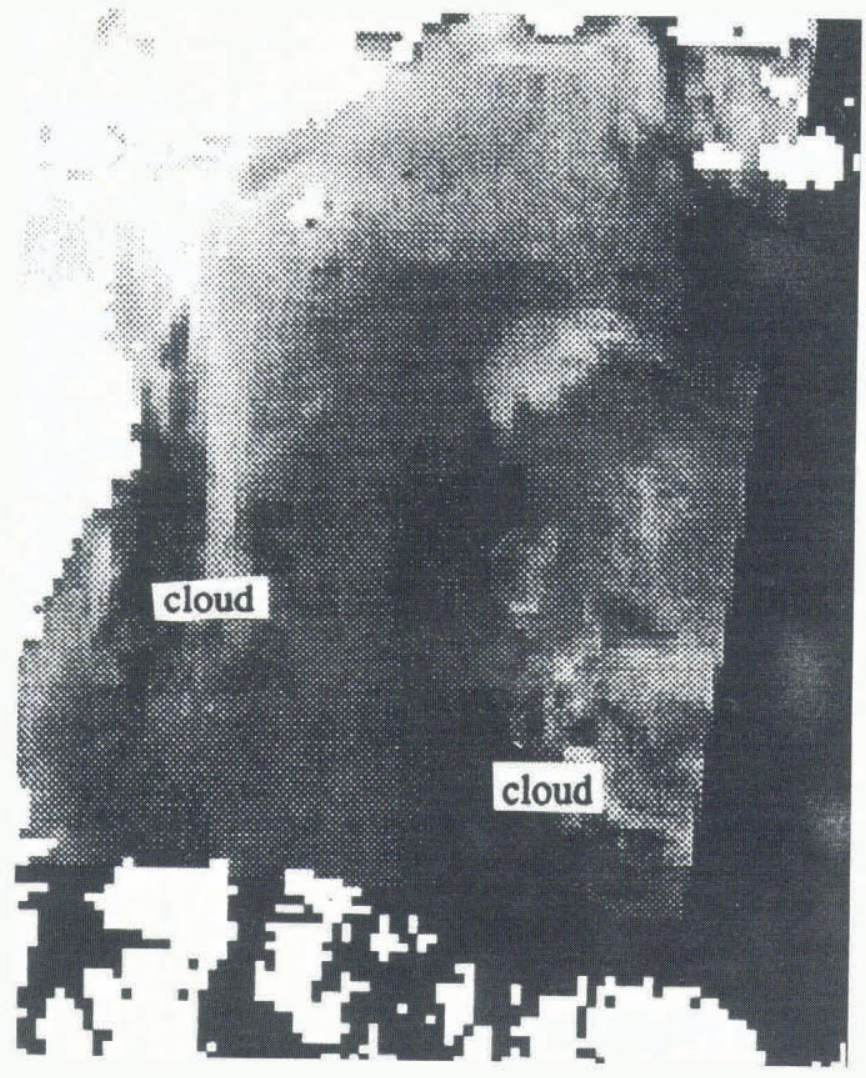

a

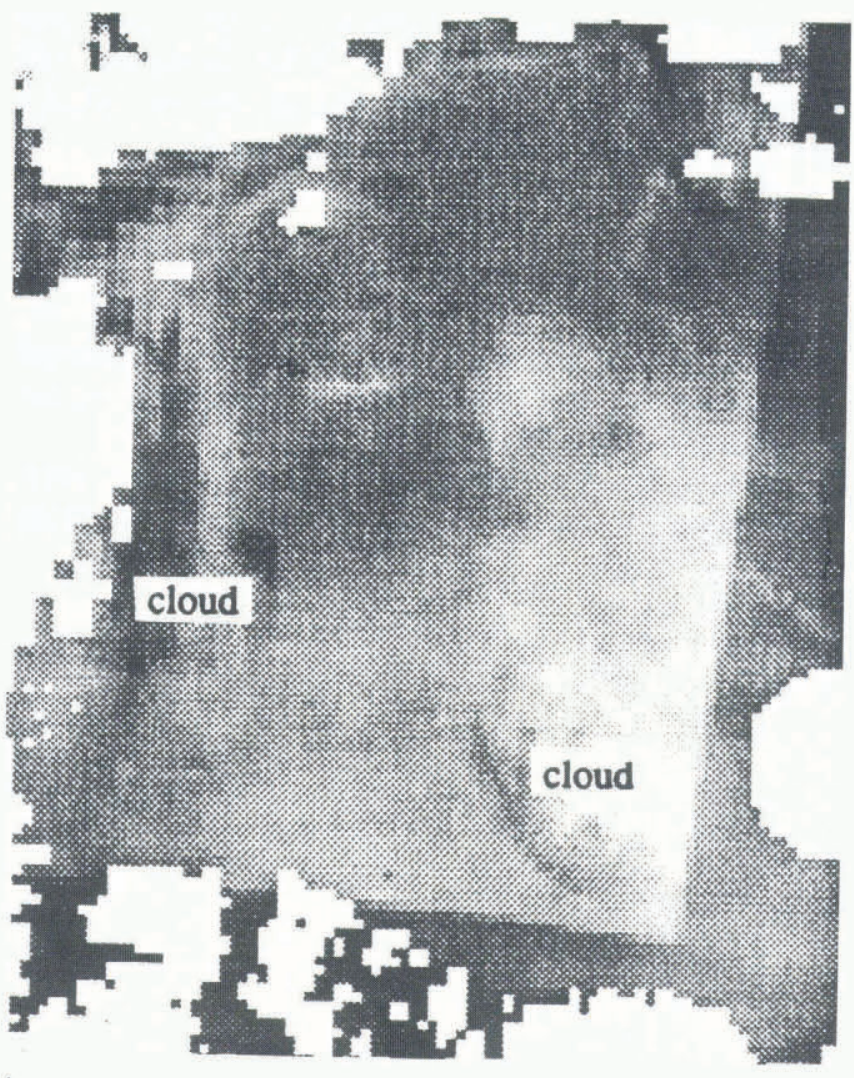

b

Fig. 5. Image of AVHRR temperatures (a) and the image resulting from $T_{\text {ice(AVHRR) minus }} T_{\text {ice(19V) }}$ (b). Examples of apparent clouds (based on manual interpretation of $T_{\mathrm{ice}(\mathrm{AVHRR})}$ ) are labeled. The temperature range in $(b)$ is about $35 K$. Geographic area shown is the same as that in Figure 2. 


\section{CONCLUSIONS}

We demonstrate how AVHRR and passive microwave imagery can be used to: (1) adjust AVHRR- derived temperatures to yield ice-only temperatures; (2) "calibrate" the passive microwave data to permit the calculation of ice pack temperatures from the microwave brightness temperatures; and (3) provide an additional tool for cloud mapping during winter. The most direct uses for microwave-derived temperatures may be in ice modeling, as a way to validate energy-balance calculations of snow/ice interface temperatures and surface temperatures, and also as a tool to refine passive microwave classifications of ice type. We have no means to determine absolute accuracy of the remotely sensed temperatures derived here, although comparison to climatological data suggest that the temperatures are reasonable. A more precise comparison is planned using single-orbit SSM/I data combined with buoy and ice station observations, and with data collected during the 1992 Seasonal Sea Ice Monitoring and Modelling Site (SIMMS) field program.

\section{ACKNOWLEDGEMENTS}

This work was supported by NASA grants NAGW-2158 and NAGW-2407 (University of Washington subcontract No. 721566). We thank Florence Fetterer and Jeff Hawkins for providing the AVHRR imagery, the National Snow and Ice Data Center for the SSM/I data, and Micaela Reddy for drafting assistance.

\section{REFERENCES}

Blanchet, J. and R. List. 1983. Estimation of optical properties of Arctic haze using a numerical model. Atmosphere-Ocean, 21, $444-465$.

Cavalieri, D.J., P. Gloersen and W.J. Campbell. 1984. Determination of sea ice parameters with the NIM-
BUS-7 SMMR. 7. Geophys. Res., 89(D4), 5355-5369.

Dozier, J. and S. G. Warren. 1982. Effect of viewing angle on the infrared brightness temperature of snow. Water Resour. Res., 18(5), 1424-1434.

Fetterer, F, and J.D Hawkins. 1991. An AVHRR data set for the Arctic leads ARI. Naval Oceanographic and Atmospheric Laboratory. Technical Note 118.

Gloersen, P. and D. J. Cavalieri. 1986. Reduction of weather effects in the calculation of sea ice concentration from microwave radiances. F. Geophys. Res. 91(C3), 3913-3919.

Key, J. and R. G. Barry. 1989. Cloud cover analysis with Arctic AVHRR data: 1. Cloud detection. 7. Geophys. Res., 94(D15), 18,521-18,535.

Key, J. and M. Haefliger. 1992. Arctic ice surface temperature retrieval from AVHRR thermal channels. 7. Geophys. Res., 97(D5), 5885-5893.

Kneizys, F.X. and 7 others. 1988. Users Guide to LOWTRAN 7. Bedford, MA, Air Force Geophysics Laboratory. (Environmental Research Papers 1010.)

Maykut, G. A. 1982. Large-scale heat exchange and ice production in the central Arctic. 7. Geophys. Res., 87(C10), 7971-7984.

National Snow and Ice Data Center (NSIDC). 1990. DMSP SSM II brightness temperature grids for the polar regions on CD-ROM. Users guide. Boulder, CO, University of Colorado. Cooperative Institute for Research in Environmental Sciences.

Parkinson, C. L., J. C. Comiso, H.J. Zwally, D.J. Cavalieri, P. Gloersen and W.J. Campbell. 1987. Arctic sea ice, 1973-1976: satellite passive-microwave observations. Washington, DC, National Aeronautics and Space Administration. (SP-489.)

Sakellariou, N. K., H. G. Leighton and Z. Li. In press. Identification of clear and cloudy pixels at high latitudes from AVHRR radiances. Int. 7. Remote Sensing.

The accuracy of references in the text and in this list is the responsibility of the authors, to whom queries should be addressed. 